\title{
Bench investigation of the accuracy of the dynamic approach in respiratory mechanics during noninvasive ventilation with different pressure support levels
}

\author{
Yuqing Chen ( $\nabla$ chenyqn69@163.com ) \\ Shanghai Chest Hospital, Shanghai Jiao Tong University \\ Yueyang Yuan \\ School of mechanical and electrical Engineering, Hu Nan City University \\ Hai Zhang \\ Shanghai chest Hospital, Shanghai Jiao Tong University \\ Feng Li \\ Shanghai Chest Hospital, Shanghai Jiao Tong University \\ Xin Zhou \\ Shanghai Chest Hospital, Shanghai Jiao Tong University
}

\section{Research article}

Keywords: dynamic respiratory mechanics; pressure-support ventilation; pulmonary compliance; resistance

Posted Date: February 21st, 2020

DOI: https://doi.org/10.21203/rs.2.24155/v1

License: (c) (1) This work is licensed under a Creative Commons Attribution 4.0 International License.

Read Full License 


\section{Abstract}

Background: Under the dynamic conditions of non-invasive mechanical ventilation, respiratory system mechanics parameters, including compliance $\left(\mathrm{C}_{\mathrm{rs}}\right)$ and airway resistance $\left(\mathrm{R}_{\mathrm{rs}}\right)$, are affected by systemic and ventilator parameters. We evaluated the accuracy of respiratory mechanics in the dynamic approach in different lung disease models during pressure support ventilation (PSV).

Methods: A Respironics V60 ventilator was connected to an active lung simulator for modeling four profiles of respiratory mechanics: normal, restrictive, obstructive and mixed obstructive/restrictive. PSV and positive end-expiration pressure (PEEP) were 2-25 $\mathrm{cm} \mathrm{H}_{2} \mathrm{O}$ and $5 \mathrm{cmH}_{2} \mathrm{O}$, respectively. Measurements were performed with an air leak of 25-28 L/min. Ventilator performance and patient-ventilator asynchrony were evaluated by measuring flow, airway pressure, and volume. $C_{r s}$ and inspiratory/expiratory resistance $\left(R_{\text {insp }} / R_{\text {exp }}\right)$ were calculated by dynamic approach.

Results: $\mathrm{C}_{\mathrm{rs}}$ was overestimated with pressure support (PS) at $5 \mathrm{~cm} \mathrm{H}_{2} \mathrm{O}$. Peak inspiratory/expiratory flow (PIF/PEF) and tidal volume $\left(\mathrm{V}_{\mathrm{T}}\right)$ was increased with PS level, while calculated $\mathrm{C}_{\mathrm{rs}}$ was decreased. At PS 10-15 $\mathrm{cm} \mathrm{H}_{2} \mathrm{O}$, the difference between calculated and preset $\mathrm{C}_{\mathrm{rs}}$ was $\leq 20 \%$ in higher resistance models (obstructive and mixed). In normal resistance conditions (restrictive and normal), the calculated $\mathrm{C}_{\mathrm{rs}}$ was always larger than the preset value significantly regardless of $P S$. Underestimations of $R_{\text {insp }}$ and $R_{\text {exp }}$ were observed at PS 5-10 $\mathrm{cmH}_{2} \mathrm{O}$. The calculation error might be controlled within $10 \%$ when PS above 15 $\mathrm{cmH}_{2} \mathrm{O}$ in higher resistance models.

Conclusion: Higher gas flow is beneficial for $\mathrm{R}_{\mathrm{rs}}$ estimation by using dynamic approach, whereas the calculation of $\mathrm{C}_{\mathrm{rs}}$ is always overestimated in normal resistance conditions.

\section{Background}

Mechanical ventilation is a lifesaving intervention that has been widely used in the management of critically ill patients for more than 50 years [1]. Analysis of individual respiratory mechanics is beneficial for guiding the ventilator setting under the conditions of pulmonary protective mechanical ventilation [2]. Recently the focus in analyzing respiratory mechanics has changed from static to dynamic conditions [3]. "Static" or "quasi-static" conditions mean that respiratory mechanics is assessed under no airflow, which is typically achieved using an end-inspiratory and an end-expiratory pause [4]. "Dynamic" conditions indicate that measurements are performed under the conditions of no flow interruption during mechanical ventilation [5]. The advantage of dynamic analysis is that respiratory maneuvers such as zero-flow occlusion and interrupting the patient's spontaneous breathing are not required.

Noninvasive positive pressure ventilation (NPPV) is applied in patients with mild to moderate respiratory failure, whereas relatively stable spontaneous breathing is necessary with air leak always present via face mask [6]. Pressure support ventilation (PSV) is one of the most used modalities in noninvasive ventilation, which also requires the patient's effort to trigger. Accurate estimation of respiratory 
mechanics during PSV is challenging, and static methods could not be adapted since airflow is always present and altered during both inspiration and expiration $[7,8]$.

The dynamic approach has been introduced in recent years and is considerably refined by the improvement of static measurement, addressing the need for an accurate estimation of lung mechanics $[9,10]$. Pulmonary compliance is assessed when the patient is passive during the inhalation phase or during the exhalation phase if the patient effort is detected during this phase [11, 12]. Meanwhile, airway resistance is measured during both the inhalation and exhalation breath phases. It is well-known that resistance changes with the level of flow through the tube for which it is being measured. That is, the higher the flow through the resistive path, the higher the resistance in the path and vice versa [8]. In this situation, the information presented to the user represents the maximum resistance experienced by the patient during the breathing phases. As with lung compliance, the estimation of resistance is made during both phases of the breath, but are more accurately if the patient is inactive during the respiration cycle for which the estimate is determined [13]]. It is typical for the patient to be relatively passive during the exhalation phase, indicating the usefulness of estimates obtained during this phase.

Despite the above wealth of knowledge, it remains unclear whether respiratory mechanics could be more accurately assessed in the dynamic approach in different lung disease models during PSV. We hypothesized that sampling of respiratory data obtained from the inspiration and expiration phases would improve precision in estimating respiratory system mechanics. Hence, the purpose of this study was to evaluate the measurement of dynamic mechanics and to test this approach during PSV with air leak in different lung models. Our findings demonstrate that controlling dynamic respiratory mechanics could help monitor pulmonary compliance and resistance continuously in spontaneously breathing patients under PSV.

\section{Methods}

\section{Procedure}

The ventilator was connected to the lung simulator by a standard disposable corrugated circuit (length, $2.0 \mathrm{~m}$ ). All ventilators were assessed with a dry circuit; humidifiers as well as heat and moisture exchangers were removed. All tests were conducted in October 2018. The average altitude of the test area was $3-5 \mathrm{~m}$; daytime temperature was $22-25^{\circ} \mathrm{C}$, with $80-85 \%$ relative humidity. There was no obvious convection indoors.

\section{Lung models}

The ASL 5000 Breathing Simulator (IngMar Medical Ltd, USA) features a computerized lung simulator comprising a piston moving in a cylinder. The stimulator comprised a single-compartment based on a report by Beloncle and colleagues [14]. The conditions of respiratory mechanics were adjusted to simulate an adult patient placed in the semi-recumbent position (inclination of $45^{\circ}$ ). Four conditions of respiratory mechanics were preset: obstructive, same inspiratory and expiratory $R_{r s}\left(R_{\text {insp }}=R_{\text {exp }}=20\right.$ 
$\mathrm{cmH}_{2} \mathrm{O} / \mathrm{L} / \mathrm{s}$ ), static $\mathrm{C}_{\mathrm{rs}}$ [compliance] at $50 \mathrm{~mL} / \mathrm{cmH}_{2} \mathrm{O}$ and a breathing rate of 15 breaths/min; severely restrictive, $\mathrm{R}_{\text {insp }}=\mathrm{R}_{\text {exp }}=5 \mathrm{cmH}_{2} \mathrm{O} / \mathrm{L} / \mathrm{s}$, static $\mathrm{C}_{\mathrm{rs}}$ at $25 \mathrm{~mL} / \mathrm{cmH}_{2} \mathrm{O}$ and a breathing rate of $30 \mathrm{breaths} / \mathrm{min}$; mixed obstructive and restrictive, $R_{\text {insp }}=R_{\text {exp }}=20 \mathrm{cmH}_{2} \mathrm{O} / \mathrm{L} / \mathrm{s}$, static $C_{r s}$ at $25 \mathrm{~mL} / \mathrm{cmH}_{2} \mathrm{O}$ and a breathing rate of 15 breaths/min; normal, $R_{\text {insp }}=R_{\text {exp }}=5 \mathrm{cmH}_{2} \mathrm{O} / \mathrm{L} / \mathrm{s}$, static $\mathrm{C}_{\mathrm{rs}}$ at $50 \mathrm{~mL} / \mathrm{cmH}_{2} \mathrm{O}$ and a breathing rate of 15 breaths/min. Inspiratory times were $0.8 \mathrm{~s}$ and $1.6 \mathrm{~s}$ for the severely restrictive and remaining three conditions, respectively [14-16]. The following parameters were based on a previous report [17]. The patient's inspiratory effort was $-5 \mathrm{cmH}_{2} \mathrm{O}$ for the normal, obstructive and mixed obstructive/restrictive conditions, while $-10 \mathrm{cmH}_{2} \mathrm{O}$ was used in the severely restrictive condition. Pressure reduction produced in $300 \mathrm{~ms}$ following the initiation of an obstructed inspiratory effort was $-5 \mathrm{cmH}_{2} \mathrm{O}$. A semi-sinusoidal inspiratory waveform was selected with rise and release times each of $50 \%$ and an inspiratory hold time of $0 \%$. The simulator integrates user-controlled leaks using a plateau exhalation valve (PEV). Air leak was controlled between 24 and $26 \mathrm{~L} / \mathrm{min}$ with $20 \mathrm{cmH}_{2} \mathrm{O}$ peak airway pressure; inspired oxygen fraction $\left(\mathrm{F}_{1} \mathrm{O}_{2}\right)$ was maintained at 0.21 for various measurements.

The patient-mask interface was simulated by a mannequin head. Endotracheal tubes (inner diameter, $22 \mathrm{~mm}$ ) placed in the mouth and nostrils directed the gas from facemask to simulator. An oro-nasal facemask without exhalation ports (BestFit ${ }^{\text {TM }}$; Curative Medical Inc., USA) was fastened firmly to the mannequin head with standard straps. A leak flow below 1-2 L/min was obtained at $20 \mathrm{cmH}_{2} \mathrm{O}$ positive pressure after PEV removal (Fig S1).

\section{Ventilator settings}

A Respironics V60 Bilevel Ventilator (Philips, USA) was linked to the lung simulator via $2.0 \mathrm{~m}$ long singleuse, single limb, corrugated circuit with a PEV. This bench study was performed with a dry circuit.

The ventilator was calibrated and configured in the PSV mode. Ventilator parameters were set according to various profiles of respiratory mechanics: positive end-expiratory pressure (PEEP) and pressure support (PS) levels were $5 \mathrm{cmH}_{2} \mathrm{O}$ and 2-25 $\mathrm{cmH}_{2} \mathrm{O}$ (above PEEP level), respectively. A back-up respiratory rate of 10 breaths/min was employed, with a maximal duration of the inspiratory phase of $2.0 \mathrm{~s}$. A shorter inspiratory rise time was selected but avoiding overshoot $[18,19]$. Trigger sensitivity and cycling criteria were auto-adjusted (digital Auto-Trak ${ }^{\mathrm{TM}}$ ) [17].

\section{Data Collection}

After baseline airway pressure stabilization, air leaks from the PEV were supplemented to the system, with $\geq 5 \mathrm{~min}$ allowed for ventilator/simulator synchronization. In case of synchronization failure, sensitivity and/or inspiratory effort were changed. If synchronization remained unachievable, the ventilator was regarded as not fit for assisted ventilation at that level of leak. Upon stabilization, 10 breaths were recorded at 1-min intervals. After each setting adjustment, 10 measurements were recorded 
per case. Offline assessment of all breaths was carried out with the software provided with the ASL 5000 Breathing Simulator.

In the inspiratory phase, peak inspiratory flow (PIF), end-inspiration pressure (EIP) and inspiratory time $\left(T_{1}\right)$ were measured by the simulator, as well as the tidal volume $\left(\mathrm{V}_{\mathrm{T}}\right)$. Peak expiratory flow $(\mathrm{PEF})$ and total PEEP were recorded in the expiration phase. The driving pressure $(\triangle P)$ was calculated as: EIP - PEEP (Fig S2).

The parameters of respiratory mechanics were assessed, as major determinants of the interaction between the patient and ventilator. $\mathrm{C}_{\mathrm{rs}}$ was calculated as the ratio between $\mathrm{V}_{\mathrm{T}}$ and driving pressure. Eq. 1 represents this relationship:

$\mathrm{C}_{\mathrm{rs}}=\mathrm{V}_{\mathrm{T}} /(\mathrm{EIP}-\mathrm{PEEP})(1)$

Inspiratory resistance $\left(R_{\text {insp }}\right)$ was calculated by two clinically useful equations:

$P_{\text {Ers insp }}=\left(V_{T}-V_{P I F}\right) / C_{r s}(2)$

$\mathrm{R}_{\text {insp }}=\left[\mathrm{P}_{\mathrm{PIF}}-\left(\right.\right.$ EIP- $\left.\left.\mathrm{P}_{\text {Ers insp }}\right)\right] /($ PIF-Flow trig $)(3)$

where $P_{\text {Ers insp }}$ is the airway pressure necessary to overcome the elastic property in the inhalation phase. Expiratory resistance $\left(R_{\text {exp }}\right)$ was also calculated by two clinically useful equations:

$P_{\text {Ers exp }}=\left(V_{T}-V_{P E F}\right) / C_{r s}(4)$

$R_{\text {exp }}=\left[P_{P E F}-\left(\right.\right.$ EIP- $\left.\left.P_{\text {Ers exp }}\right)\right] / P E F(5)$

where $\mathrm{P}_{\text {Ers exp }}$ is the airway pressure required to overcome the elastic property in the exhalation phase[20].

\section{Statistical analysis}

Data are mean \pm standard deviation (SD). Normality of the data was assessed by the Shapiro-Wilk test. Statistical analysis was carried out with SPSS version 11.0 (SPSS; Chicago, IL, USA). Comparisons of variables at different settings were performed by one-way randomized block ANOVA. Two-tailed $P<0.01$ was considered statistically significant. Differences between calculated and preset values were expressed as the percentages of preset values. The smaller the error, the more clinically significant the parameter. The purpose of this study was to observe the error size, which should be optimally $<10 \%$.

\section{Results}

\section{Estimated vs. measured compliance $\left(\mathrm{C}_{\mathrm{rs}}\right)$ at different pressure support levels in various models}


The measurement results of dynamic mechanics at all PS levels are summarized in Tables 1-4. $C_{r s}$ and $R_{r s}\left(R_{\text {insp }}\right.$ and $\left.R_{\text {exp }}\right)$ were calculated according to Eq 1-5, respectively, as described above, with PEEP kept constant at end-expiration. At lower PS level and high inspiratory effort (such as severely restrictive), $\mathrm{C}_{\mathrm{rs}}$ was overestimated and $\mathrm{R}_{\mathrm{rs}}$ was underestimated grossly (Fig $1 \mathrm{C}$ and Table 3). Elevated PS level was associated with higher PIF/PEF and tidal volume, while the measured $\mathrm{C}_{\mathrm{rs}}$ was decreased. In the particular at a pressure support of $10-15 \mathrm{cmH}_{2} \mathrm{O}$, the difference between calculated and preset $\mathrm{C}_{\mathrm{rs}}$ was $\leq 20 \%$ in higher resistance models (obstructive and mixed; Fig 1 and Tables 1 and 2). In normal resistance conditions (severely restrictive and normal), calculated $\mathrm{C}_{\mathrm{rs}}$ was always overestimated significantly at all PS levels (Fig 1 and Tables 3 and 4).

\section{Estimated vs. preset inspiratory and expiratory resistance at different pressure support levels in various models}

In all lung models, $\mathrm{R}_{\text {insp }}$ was underestimated observed at PS levels below $15 \mathrm{cmH}_{2} \mathrm{O}$. The calculated value generally increased with PS level. The calculated error might be controlled by about $10 \%$ when PS above $15 \mathrm{cmH}_{2} \mathrm{O}$ in higher resistance conditions (Fig 2).

Similar results were obtained for calculated $\mathrm{R}_{\text {exp }}$. The difference between calculated and preset values was reduced remarkably with increasing PS level. $R_{\text {exp }}$ error was below $10 \%$ after PS $\geq 15 \mathrm{cmH}_{2} \mathrm{O}$ (Fig 2). Fig $2 \mathrm{D}$ shows that in normal adults, higher PS level $\left(>7 \mathrm{cmH}_{2} \mathrm{O}\right)$ lead to larger $\mathrm{V}_{\mathrm{T}}$ and loss of control (runaway), the ventilator could not output appropriate supporting; therefore, only three points are represented.

\section{Discussion}

The present bench study yielded the following main findings: 1) the accuracy of respiratory mechanics $\left(\mathrm{R}_{\mathrm{rs}}\right.$ and $\left.\mathrm{C}_{\mathrm{rs}}\right)$ was affected by PS level during assist ventilation without interference from spontaneous breathing; 2) in the obstructive condition, the calculated $C_{r s}$ error was minimal at a PS level of 10-15 $\mathrm{cmH}_{2} \mathrm{O}$, and the calculated $\mathrm{R}_{\text {insp }}$ and $\mathrm{R}_{\text {exp }}$ errors were below $10 \%$; and 3$) \mathrm{C}_{\mathrm{rs}}$ was always overestimated in the restrictive and normal adult models, accompanied by $\mathrm{R}_{\mathrm{rs}}$ underestimation.

Currently, many mechanical ventilators provide a brief end-inspiration and end-expiration occlusion that allows measurements with no flow and a static tidal volume. Static measurements are performed by a standard and classic method in which data represent the static mechanical properties of the respiratory system. It is essential for the patient effort, whether due to disease, sedation or paralysis, not to be allowed during static measurements [21-23]. In addition, it is assumed that parameters of respiratory mechanics (compliance and resistance) are linear between end-inspiration and end-expiration for calculating static compliance $[24,25]$. However, in spontaneously breathing patients, the inspiratory effort 
always exists. The airway pressure generated by inspiratory muscles $\left(P_{\text {mus }}\right)$ mainly depends on diaphragm activity and the driving pressure output by the ventilator. Since $P_{\text {mus }}$ varies with time and reveals different shapes among individuals, analyzing such respiratory system mechanics is very difficult [26].

Dynamic measurements may assess the mechanical characteristics of the respiratory system during variable gas flow with recent advances in monitoring technology and sophisticated software. Online estimation at the bedside is a helpful diagnostic tool for assisting therapeutic decisions and adjusting the ventilator settings $[7,27]$. Dynamic measurements include the run-away method and the least square fitting (LSF) technique. The run-away method was first proposed by Younes to analyze lung mechanics [28]. In a station with run-away occurrence, the whole respiratory system is in an unstable condition, and larger tidal volume and higher inspiratory flow are observed frequently. Therefore, the patient feels very uncomfortable and is unable to tolerate mechanical ventilatory support. Although this technique may provide satisfactory results, it is not optimal for bedside monitoring [29]. Recursive least squares (RLS) is a modified LSF technique that derives values for $\mathrm{C}_{\mathrm{rs}}$ and $\mathrm{R}_{\mathrm{rs}}$ by solving the linear regression equation, in which Paw, $\mathrm{V}_{\mathrm{T}}$ and flow measurements are multiple times (up to $100-200 \mathrm{~Hz}$ ) those recorded during the respiratory cycle. To overcome difficulties in estimating mechanics in spontaneously breathing subjects by the RLS method, Zhao et al developed an RLS method termed the adaptive time slice method (ATSM) $[30,31]$.

During pressure-preset ventilation such as PSV, the airway pressure waveform is rectangular while inspiratory flow varies; the dynamics of lung filling and emptying can be exactly described by exponential equations, and is affected by ventilatory parameters and respiratory system characteristics [16]. Iotti et al found that calculated $\mathrm{C}_{\mathrm{rs}}$ could be affected by the PS level [32]. With low PS level and high spontaneous breathing activity, calculated $C_{r s}$ was overestimated while $R_{r s}$ was underestimated; similar $C_{r s}$ values were obtained at equal $\mathrm{V}_{\mathrm{T}}$ during PSV with controlled mandatory ventilation (CMV) at constant flow [32]. In this bench study, the lung simulator was set to simulate an adult with normal body weight $(65-70 \mathrm{~kg})$, assuming that static $\mathrm{C}_{\mathrm{rs}}$ and $\mathrm{R}_{\mathrm{rs}}$ remained constant throughout any given breath. We demonstrated that calculated $\mathrm{C}_{\mathrm{rs}}$ gradually decreased with increasing PS level. Only at a tidal volume of 400-600 ml (7$8 \mathrm{ml} / \mathrm{kg}$ ), adjusted by pressure support level, the error of calculated $C_{\mathrm{rs}}$ was $\leq 20 \%$ the preset value in obstructive conditions.

The advantage of PSV is that the variable inspiratory flow can meet the patient's demand and improve comfort. PSV must be triggered by the patient's inspiratory effort. Usually, the patient's effort is detected by a pressure trigger or a flow trigger. During noninvasive ventilation, the most used trigger mechanism on Respironics BiPAP devices is the flow shape-signal technique, which applies a mathematical model derived from the flow and pressure signals, with better tolerance and reduced trigger asynchrony [14, 33]. Based on this technique, breath initiation during NPPV is more likely to be triggered by a flow change and not pressure alteration in the ventilator circuit. When assisted ventilation is activated and airway pressure starts to increase, the initial flow is not zero. In this case, the measured inspiratory resistance would be 
more accurate using the modified equation. As shown above, the measurement errors for $R_{\text {insp }}$ and $R_{\exp }$ were less than $10 \%$ of the corresponding preset values in the obstructive model at PS levels $\geq 15 \mathrm{cmH}_{2} \mathrm{O}$.

The dynamic approach was selected because it requires neither special maneuvers nor particular flow patterns, and does not rely on the amplitude and shape of $\mathrm{P}_{\text {mus }}$. However, $\mathrm{C}_{\mathrm{rs}}$ calculation is restricted to the tidal volume since the equation represents the ratio between tidal volume and driving pressure, which is defined as the difference between plateau pressure and total PEEP [34]. In this bench study, the simulator was ventilated in the pressure support mode with an exponential decay of inspiratory flow waveform. The driving pressure was calculated as EIP-PEEP. During PSV, $\mathrm{P}_{\mathrm{aw}}$ is constant at the endinspiration phase which the inspiratory flow is reduced from the PIF gradually, EIP is obtained when the inhalation turns to exhalation. .The inspiratory and expiratory resistance were calculated by modified specific equations over the full respiratory cycle. [In this study, the Paw-time curve obtained during PSV is shown in Fig S2: in the middle and late periods of the inspiratory phase, Paw was constant while inspiratory flow decreased gradually. This made it possible to collect Paw values at the end of inspiration as EIP.](delete)

The main limitation of this bench study was that the linear model was selected, which as defined in the equation of motion assumes that $\mathrm{C}_{\mathrm{rs}}$ and $\mathrm{R}_{\mathrm{rs}}$ remain constant throughout the respiratory cycle. In addition, actual clinical are required to confirm the current findings.

\section{Conclusions}

In the present bench study, estimation of the respiratory mechanics by using modified dynamic approach was firstly introduced to determine compliance and resistance in spontaneously breathing patients under PSV. Different from the occlusion method, the modified dynamic approach is more effective and could monitor respiratory mechanics noninvasively and continuously in obstructive conditions. It is important to adjust PS level and pool the respiratory data of consecutive breaths. The estimated accuracy of system compliance clearly depends on the volume status (e.g. 400-600 ml) in obstructive patients, while resistance calculation is significantly flow-dependent.

\section{Abbreviations}

Crs:compliance; Rrs:resistance; PSV:pressure support ventilation; PS:pressure support; NPPV:Noninvasive positive pressure ventilation; PSV:Pressure support ventilation; PIF:peak inspiratory flow; EIP:endinspiration pressure; SD:standard deviation.

\section{Declarations}

\section{Ethics approval and consent to participate}

This article does not contain any studies with human participants or animals performed by any of the authors. 


\section{Consent for publication}

Not applicable

\section{Availability of data and materials}

The datasets used and/or analysed during the current study are available from the corresponding author on reasonable request.

\section{Competing interests}

The authors declare no conflict of interest

\section{Funding}

This study was funded by the "Star of Jiaotong University" program of Shanghai Jiao Tong university medical and industrial cross research Fund Project [grant no YG2019ZDB08].

\section{Authors' contributions}

Chen YQ have made contributions to the conception and have drafted the work or substantively revised it; Yuan $\mathrm{YY}$ have made contributions to design of the work; Zhang $\mathrm{H}$ have made contributions to the acquisition, analysis; Li $\mathrm{F}$ and Zhou $\mathrm{X}$ have made contributions to interpretation of data. All authors read and approved the final manuscript.

\section{References}

1. Dellaca RL, Veneroni C, Farre R. Trends in mechanical ventilation: are we ventilating our patients in the best possible way? Breathe (Sheffield, England). 2017;13:84-98. doi: 10.1183/20734735.007817

2. Gattinoni L, Eleonora C, Caironi P. Monitoring of pulmonary mechanics in acute respiratory distress syndrome to titrate therapy. Current opinion in critical care. 2005;11:252-8. doi: 10.1097/01.ccx.0000160773.43122.35

3. Stenqvist $\mathrm{O}$, Odenstedt $\mathrm{H}$, Lundin $\mathrm{S}$. Dynamic respiratory mechanics in acute lung injury/acute respiratory distress syndrome: research or clinical tool? Current opinion in critical care. 2008;14:8793. doi: 10.1097/MCC.0b013e3282f3a166

4. Rossi A, Gottfried SB, Zocchi L, Higgs BD, Lennox S, Calverley PM, et al. Measurement of static compliance of the total respiratory system in patients with acute respiratory failure during mechanical ventilation. The effect of intrinsic positive end-expiratory pressure. The American review of respiratory disease. 1985;131:672-7. doi: 10.1164/arrd.1985.131.5.672

5. Mols G, Priebe HJ, Guttmann J. Alveolar recruitment in acute lung injury. British journal of anaesthesia. 2006;96:156-66. doi: 10.1093/bja/aei299 
6. Akashiba $T$, Ishikawa $Y$, Ishihara $H$, Imanaka $H$, Ohi M, Ochiai R, et al. The Japanese Respiratory Society Noninvasive Positive Pressure Ventilation (NPPV) Guidelines (second revised edition). Respiratory investigation. 2017;55:83-92. doi: 10.1016/j.resinv.2015.11.007

7. Zhao Z, Eger M, Handzsuj T, Ranieri VM, Appendini L, Micelli C, et al. Noninvasive method for measuring respiratory system compliance during pressure support ventilation. Conference proceedings : Annual International Conference of the IEEE Engineering in Medicine and Biology Society IEEE Engineering in Medicine and Biology Society Annual Conference. 2011;2011:3808-11. doi: 10.1109/iembs.2011.6090772

8. Henderson WR, Sheel AW. Pulmonary mechanics during mechanical ventilation. Respiratory physiology \& neurobiology. 2012;180:162-72. doi: 10.1016/j.resp.2011.11.014

9. Lichtwarck-Aschoff M, Kessler V, Sjostrand UH, Hedlund A, Mols G, Rubertsson S, et al. Static versus dynamic respiratory mechanics for setting the ventilator. British journal of anaesthesia. 2000;85:57786. doi: $10.1093 / \mathrm{bja} / 85.4 .577$

10. Guttmann J. Analysis of respiratory mechanics during artificial ventilation. Biomedizinische Technik Biomedical engineering. 1998;43:107-15. doi: 10.1515/bmte.1998.43.4.107

11. Lutfi MF. The physiological basis and clinical significance of lung volume measurements. Multidisciplinary respiratory medicine. 2017;12:3. doi: 10.1186/s40248-017-0084-5

12. Grinnan DC, Truwit JD. Clinical review: respiratory mechanics in spontaneous and assisted ventilation. Critical care (London, England). 2005;9:472-84. doi: 10.1186/cc3516

13. Yamauchi Y, Kohyama T, Jo T, Nagase T. Dynamic change in respiratory resistance during inspiratory and expiratory phases of tidal breathing in patients with chronic obstructive pulmonary disease. International journal of chronic obstructive pulmonary disease. 2012;7:259-69. doi: 10.2147/copd.s30399

14. Beloncle F, Akoumianaki E, Rittayamai N, Lyazidi A, Brochard L. Accuracy of delivered airway pressure and work of breathing estimation during proportional assist ventilation: a bench study. Annals of intensive care. 2016;6:30. doi: 10.1186/s13613-016-0131-y

15. Bosma KJ, Read BA, Bahrgard Nikoo MJ, Jones PM, Priestap FA, Lewis JF. A Pilot Randomized Trial Comparing Weaning From Mechanical Ventilation on Pressure Support Versus Proportional Assist Ventilation. Critical care medicine. 2016;44:1098-108. doi: 10.1097/ccm.0000000000001600

16. Marini JJ, Crooke PS, 3rd, Truwit JD. Determinants and limits of pressure-preset ventilation: a mathematical model of pressure control. Journal of applied physiology (Bethesda, Md : 1985). 1989;67:1081-92. doi: 10.1152/jappl.1989.67.3.1081

17. Chen Y, Cheng K, Zhou X. Effectiveness of Inspiratory Termination Synchrony with Automatic Cycling During Noninvasive Pressure Support Ventilation. Medical science monitor : international medical journal of experimental and clinical research. 2016;22:1694-701. doi: 10.12659/msm.896059

18. Hess DR. Ventilator waveforms and the physiology of pressure support ventilation. Respiratory care. 2005;50:166-86; discussion 83-6. doi: 
19. Yamada Y, Du HL. Analysis of the mechanisms of expiratory asynchrony in pressure support ventilation: a mathematical approach. Journal of applied physiology (Bethesda, Md : 1985). 2000;88:2143-50. doi: 10.1152/jappl.2000.88.6.2143

20. Karamolegkos N, Albanese A, Isaza F, Chbat NW. Patient emulator: a tool for testing mechanical ventilation therapies. Conference proceedings: Annual International Conference of the IEEE Engineering in Medicine and Biology Society IEEE Engineering in Medicine and Biology Society Annual Conference. 2016;2016:4321-4. doi: 10.1109/embc.2016.7591683

21. Macklem PT. The mechanics of breathing. American journal of respiratory and critical care medicine. 1998;157:S88-94. doi: 10.1164/ajrccm.157.4.nhlbi-5

22. Barberis L, Manno E, Guerin C. Effect of end-inspiratory pause duration on plateau pressure in mechanically ventilated patients. Intensive care medicine. 2003;29:130-4. doi: 10.1007/s00134-0021568-z

23. Lucangelo U, Bernabe F, Blanch L. Respiratory mechanics derived from signals in the ventilator circuit. Respiratory care. 2005;50:55-65; discussion -7. doi:

24. Henderson WR, Chen L, Amato MBP, Brochard LJ. Fifty Years of Research in ARDS. Respiratory Mechanics in Acute Respiratory Distress Syndrome. American journal of respiratory and critical care medicine. 2017;196:822-33. doi: 10.1164/rccm.201612-2495Cl

25. Primiano FP, Jr., Chatburn RL. Zen and the art of nomenclature maintenance: a revised approach to respiratory symbols and terminology. Respiratory care. 2006;51:1458-70. doi:

26. Amato MB, Barbas CS, Medeiros DM, Magaldi RB, Schettino GP, Lorenzi-Filho G, et al. Effect of a protective-ventilation strategy on mortality in the acute respiratory distress syndrome. The New England journal of medicine. 1998;338:347-54. doi: 10.1056/nejm199802053380602

27. Terragni PP, Rosboch GL, Lisi A, Viale AG, Ranieri VM. How respiratory system mechanics may help in minimising ventilator-induced lung injury in ARDS patients. The European respiratory journal Supplement. 2003;42:15s-21s. doi: 10.1183/09031936.03.00420303

28. Younes $M$, Webster $K$, Kun J, Roberts D, Masiowski B. A method for measuring passive elastance during proportional assist ventilation. American journal of respiratory and critical care medicine. 2001;164:50-60. doi: 10.1164/ajrccm.164.1.2010068

29. Porta R, Appendini L, Vitacca M, Bianchi L, Donner CF, Poggi R, et al. Mask proportional assist vs pressure support ventilation in patients in clinically stable condition with chronic ventilatory failure. Chest. 2002;122:479-88. doi: 10.1378/chest.122.2.479

30. Lauzon AM, Bates $\mathrm{JH}$. Estimation of time-varying respiratory mechanical parameters by recursive least squares. Journal of applied physiology (Bethesda, Md : 1985). 1991;71:1159-65. doi: 10.1152/jappl.1991.71.3.1159

31. Zhao Z, Guttmann J, Moller K. Adaptive SLICE method: an enhanced method to determine nonlinear dynamic respiratory system mechanics. Physiological measurement. 2012;33:51-64. doi: 10.1088/0967-3334/33/1/51 
32. lotti GA, Braschi A, Brunner JX, Smits T, Olivei M, Palo A, et al. Respiratory mechanics by least squares fitting in mechanically ventilated patients: applications during paralysis and during pressure support ventilation. Intensive care medicine. 1995;21:406-13. doi: 10.1007/bf01707409

33. Poggi R, Appendini L, Polese G, Colombo R, Donner CF, Rossi A. Noninvasive proportional assist ventilation and pressure support ventilation during arm elevation in patients with chronic respiratory failure. A preliminary, physiologic study. Respiratory medicine. 2006;100:972-9. doi: 10.1016/j.rmed.2005.10.007

34. Lucangelo U, Bernabe F, Blanch L. Lung mechanics at the bedside: make it simple. Current opinion in critical care. 2007;13:64-72. doi: 10.1097/MCC.0b013e32801162df

\section{Tables}

Due to technical limitations, Tables 1 - 4 are only available for download from the Supplementary Files section.

\section{Supplementary File Legend}

Additional file 1(.doc); Supplementary figure

\section{Figures}



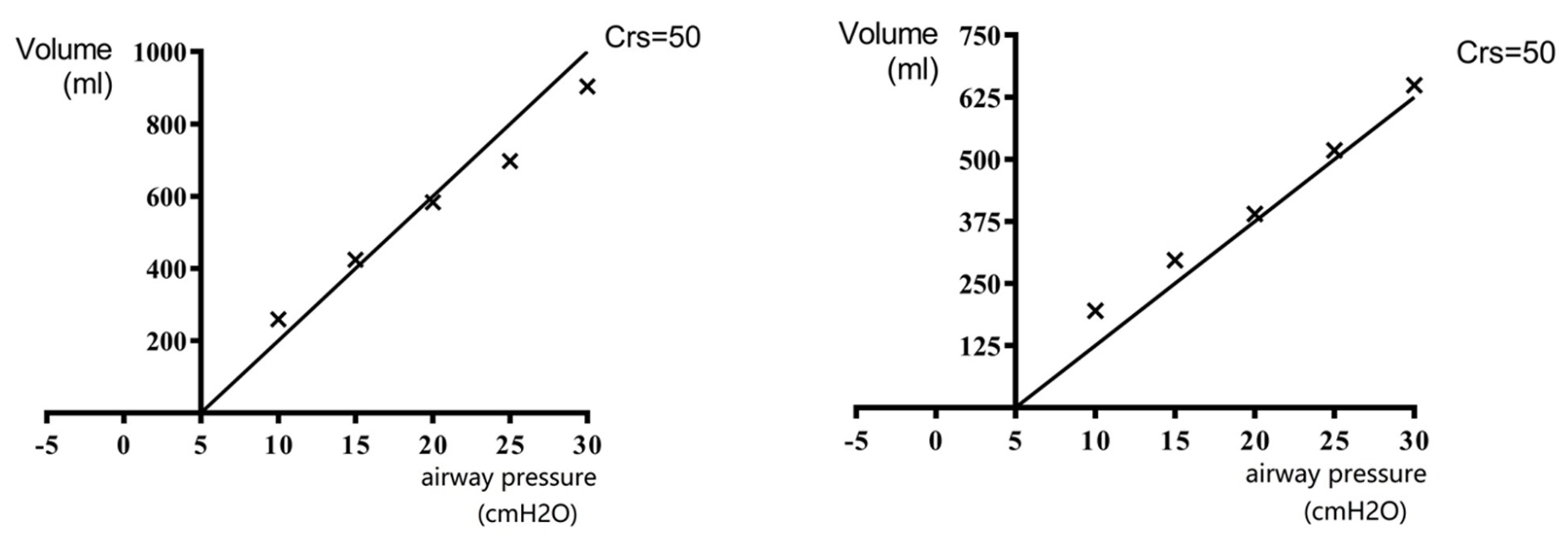

C

D
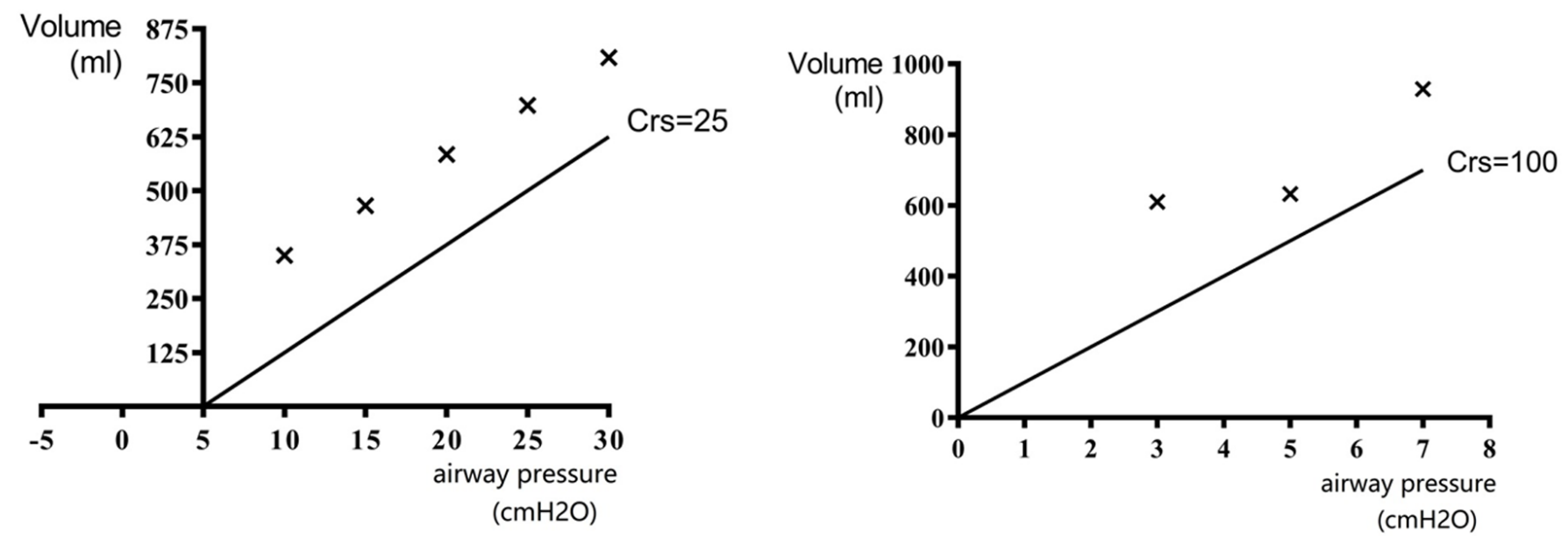

\section{Figure 1}

Comparisons of compliance (Crs) in various models at different PS levels. Obstructive (A), mixed (B), severely restrictive (C) and normal (D) models are shown. Data are mean $\pm S D$. $P<0.01$ vs. PSV for all pairwise comparisons. 
A
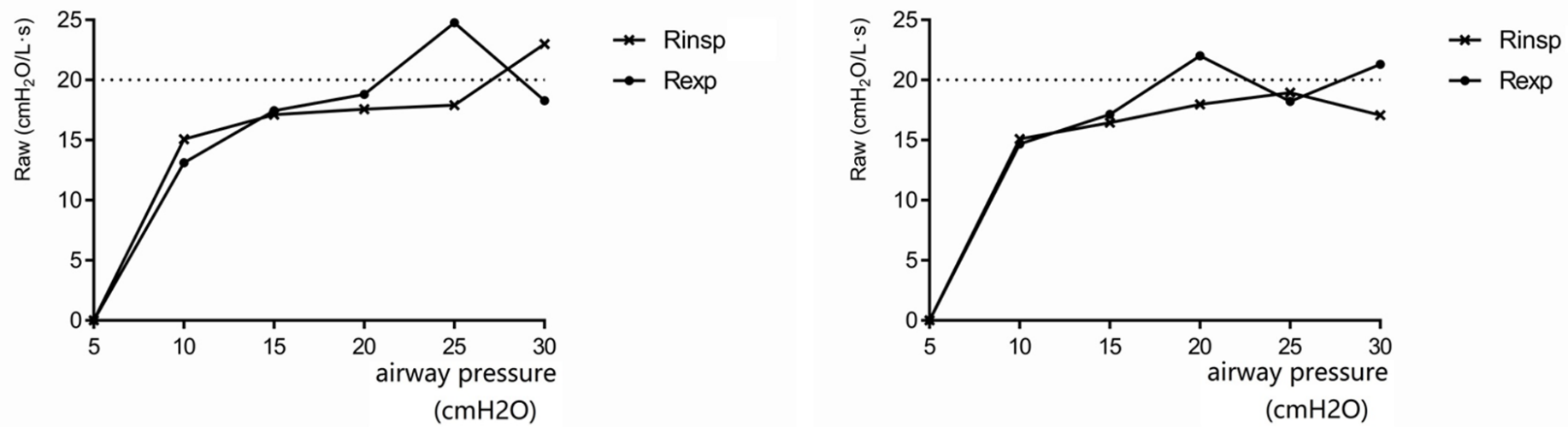

C

D
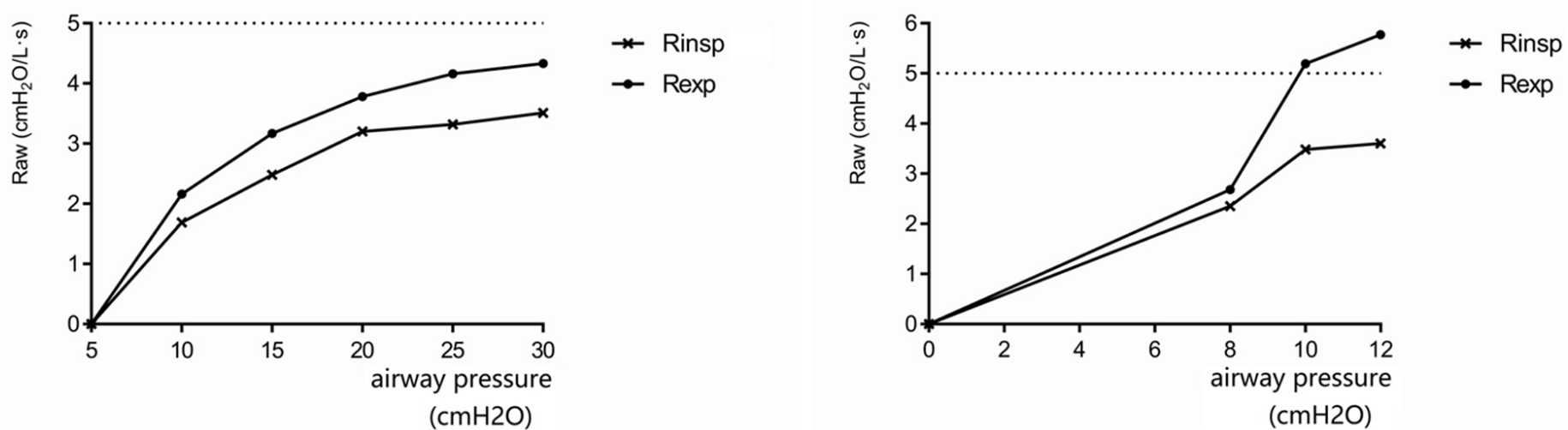

Figure 2

Comparisons of inspiratory (Rinsp) and expiratory resistance (Rexp). Obstructive (A), mixed (B), severely restrictive $(C)$ and normal $(D)$ models are shown. Data are mean $\pm S D$. $P<0.01$ vs. PSV for all pairwise comparisons. The dotted line in the figure represents the preset value of Rinsp.

\section{Supplementary Files}

This is a list of supplementary files associated with this preprint. Click to download.

- Tables14.pdf

- Additionalfile1.docx 